\title{
Small cell lung carcinoma in a patient with previously diagnosed Ménétrier's disease: Is this another neuroendocrine manifestation of the neoplastic potential of this condition?
}

\author{
Eleanor Gerada ${ }^{1}$, J urgen Gerada ${ }^{2}$, Lianne Camilleri ${ }^{3}$, Darko Babic ${ }^{4}$, J osef Micallef ${ }^{5}$ \\ 1. Division of Respiratory Medicine, Mater Dei Hospital, Msida, Malta. 2. Division of Gastroenterology, Mater Dei Hospital, \\ Msida, Malta. 3. Department of General Medicine, Mater Dei Hospital, Msida, Malta. 4. Department of Pathology, Mater Dei \\ Hospital, Msida, Malta. 5. Division of Respiratory Medicine, Mater Dei Hospital, Msida, Malta.
}

Correspondence: Eleanor Gerada. Address: Division of Respiratory Medicine, Department of General Medicine, Mater Dei Hospital Msida, Malta. Email: eleanor.gerada@gov.mt

Received: February 6, 2014

DOI : $10.5430 /$ crim.v1n2p12
Accepted: February 24, 2014

URL: http://dx.doi.org/10.5430/crim.v1n2p12

\section{Abstract}

A 73-year old man with a history of Ménétrier's disease developed a mass in the axilla. Histology revealed this to be a metastatic neuroendocrine carcinoma, most consistent with a lung primary. Computed tomography scan of the thorax showed a $28 \mathrm{~mm}$ lesion in close proximity to the right bronchus intermedius. Cytological specimen from bronchoalveolar lavage yielded small cell carcinoma cells. Serum chromogranin A and serum gastrin levels were found to be significantly elevated. Ménétrier's disease has been associated with malignancy especially neuroendocrine neoplasms. Small cell lung carcinoma is also a high grade neuroendocrine lung neoplasm. In this report we will bring forward hypotheses about possible links between the two conditions.

\section{Keywords}

Axillary lymph node metastases, Gastrin, Ménétrier's disease, Neuroendocrine tumour, Small cell lung cancer

\section{I ntroduction}

We hereby present a case of a patient known to suffer with Ménétrier's disease who developed small cell lung carcinoma. In the discussion we will bring forward hypotheses about possible links between the two conditions.

\section{Case presentation}

A 73 year old gentleman was noted to have developed a mass in the right posterior axillary fold. He had initially presented 3 years previously with dyspepsia, weight loss, bilateral lower limb oedema and hypoalbuminaemia. An oesophagogastroduodenoscopy had revealed large gastric folds involving the fundus and the body of the stomach (see Figure 1). Histology had shown pronounced foveolar hyperplasia and cystic dilatation compatible with a diagnosis of Ménétrier's disease (see Figure 2). His symptoms had resolved after a 2 month course of oral prednisolone (20mg) and a proton pump 
inhibitor, gradually gaining back 10kgs, together with normalization of his serum albumin levels. After 2 months of therapy, prednisolone was stopped and omeprazole was maintained long-term. Endoscopically, 3 months post-therapy and 1- and 2-years later, he still had prominent gastric folds albeit less pronounced, with hyperplastic gastropathy remaining a feature on histology. There was no dysplasia or malignancy of the stomach on histology a few months prior to the development of the axillary mass. Albumin levels were still normal at this stage.

An excision biopsy of the current right axillary mass was performed. Histology revealed the mass to be a lymph node extensively replaced by metastatic carcinoma. Tumour cells expressed pancytokeratins, keratin 7, TTF-1 and CD56 (see Figure 3). On the other hand, CD45, S100 protein, CD20 and keratins 5/6 were not expressed. A diagnosis of metastatic poorly differentiated neuroendocrine carcinoma, most consistent with a lung primary was made.

The patient was asymptomatic from the respiratory point of view and had no systemic symptoms. He was a lifelong smoker with a 30 pack-year history. While the pre-operative chest X-ray was reported as normal, the contrast-enhancing computed tomography (CT) scan of the trunk showed increased perihilar shadowing $(28 \mathrm{~mm})$ surrounding the right bronchus intermedius (see Figures $4 \mathrm{a}, \mathrm{b}$ ). There was no evidence of gastrointestinal neuroendocrine tumours (stomach, duodenum or pancreas); nor metastatic deposits.

Bronchoscopy revealed a normal calibre right bronchus intermedius with no intraluminal lesions. However, broncho-alveolar lavage samples yielded small-cell lung carcinoma (SCLC) cells (see Figure 5).

Analysis of circulating neuroendocrine markers of the untreated patient with SCLC showed normal levels of serum calcium, ADH and ACTH, with an elevated serum chromogranin A level of $1990 \mu \mathrm{g} / 1(<85 \mu \mathrm{g} / \mathrm{l})$ and an elevated gastrin level of $2160 \mathrm{pg} / \mathrm{ml}(<115 \mathrm{pg} / \mathrm{ml})$. 24-hour urinary 5HIAA was found to be within range.

The patient received a course of intravenous carboplatin and etoposide. A repeat CT scan showed local disease response at the right hilum with reduction in size of the right lower lobe mass measuring only $17 \mathrm{~mm}$ in diameter with no significant lymphadenopathy. However, subsequently he developed multiple cerebral and cerebellar metastases which were treated with local radiotherapy. The patient is alive 6 months after the diagnosis of metastatic SCLC, his prognosis however remains poor.

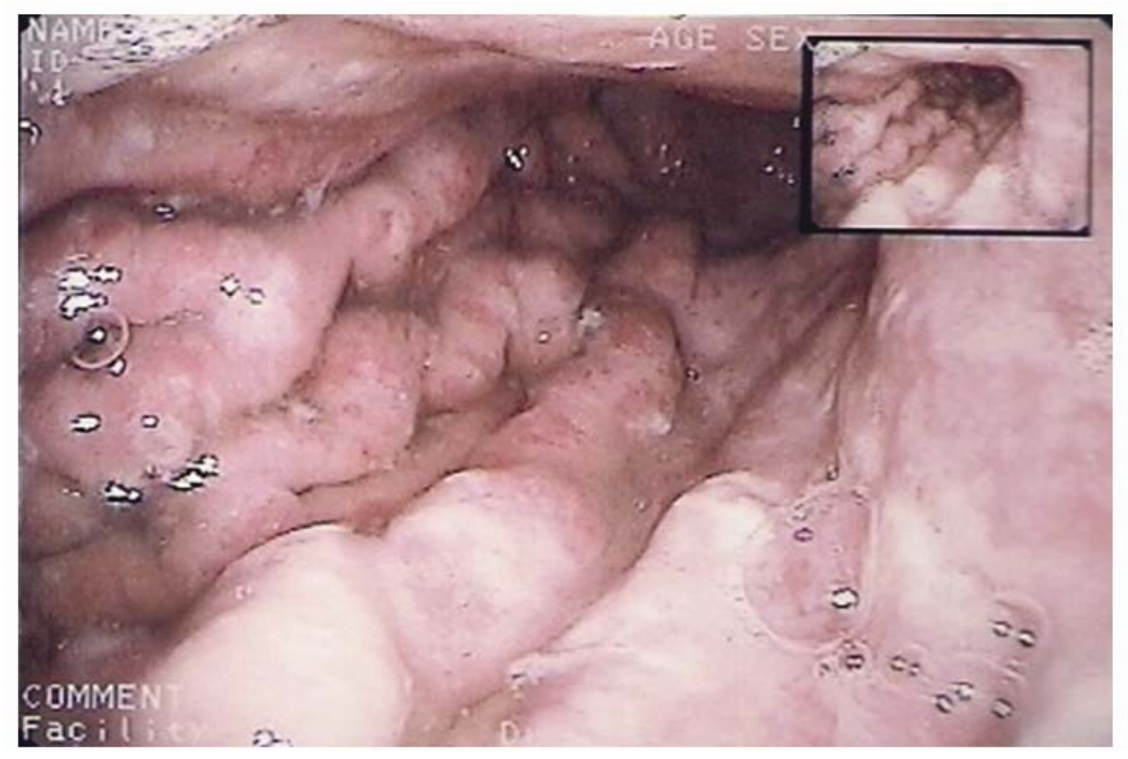

Figure 1. Oesophagogastroduodenoscopy showing giant gastric folds in the body of the stomach. 


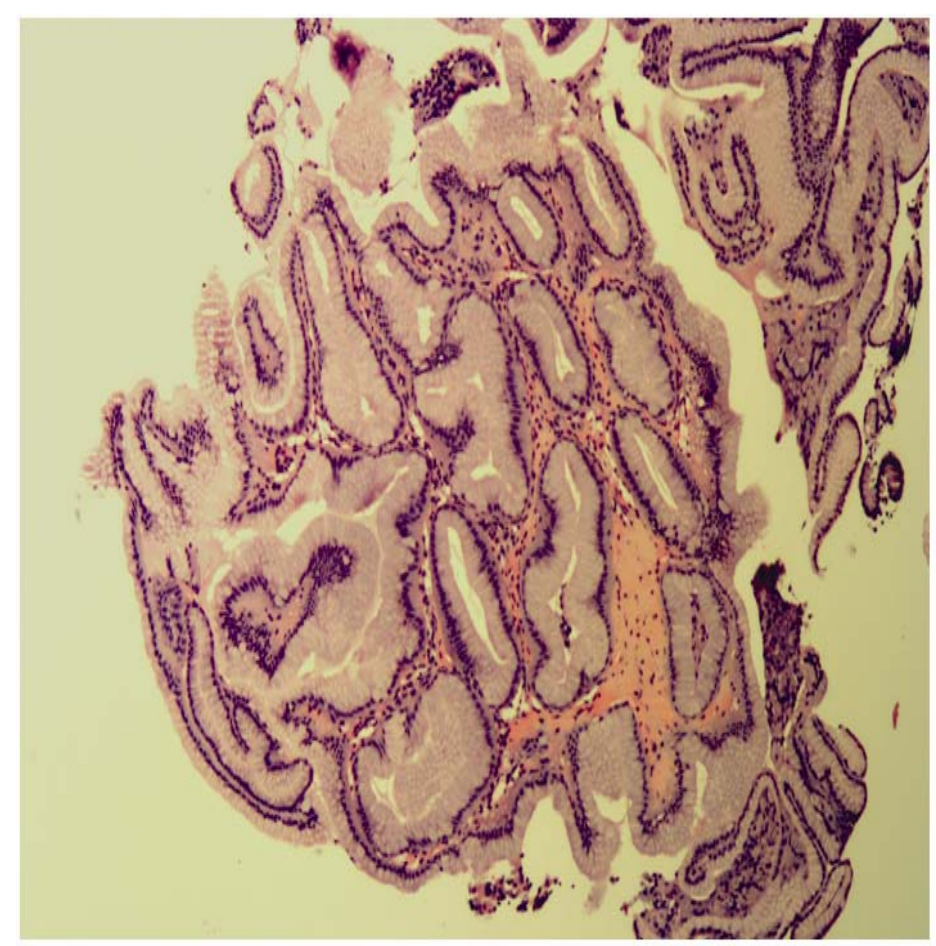

Figure 2. Biopsy from the body of the stomach showing hyperplastic gastropathy with cystic dilatation and pronounced foveolar hyperplasia (H\&E stain, $\times 100)$.

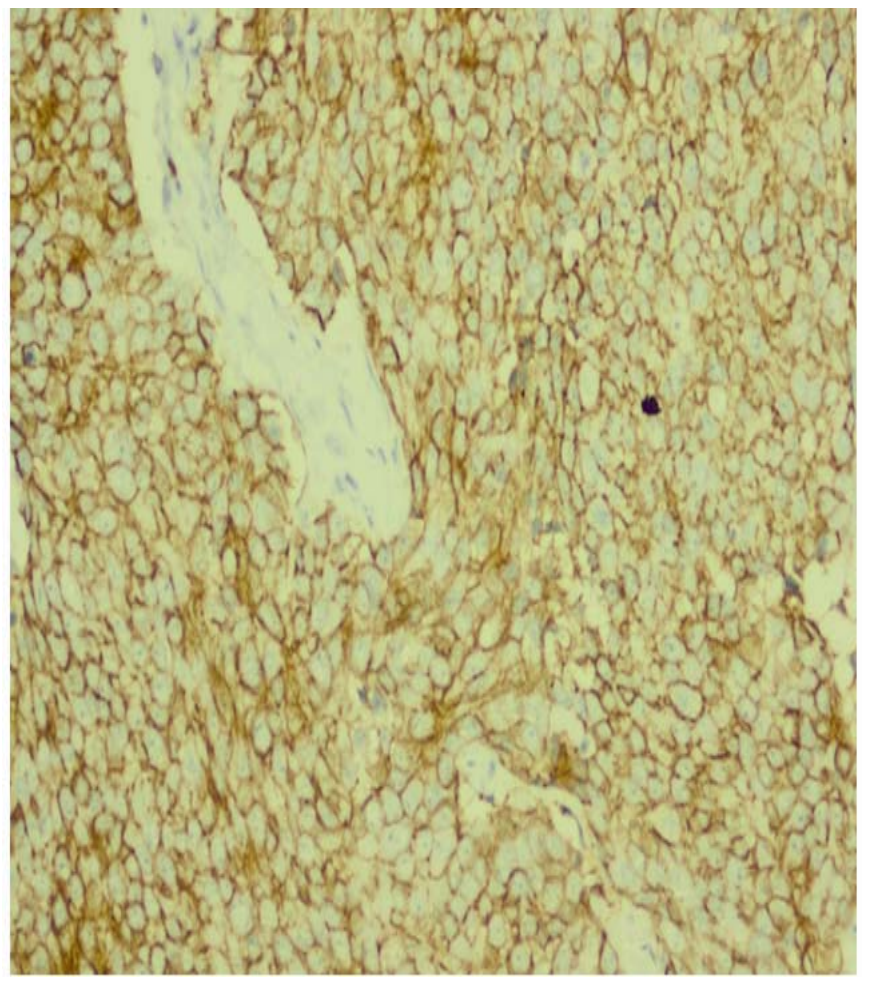

Figure 3. Positive CD56 staining $(\times 200)$ of the mass in the right posterior axillary fold, in keeping with metastases of neuroendocrine origin. 


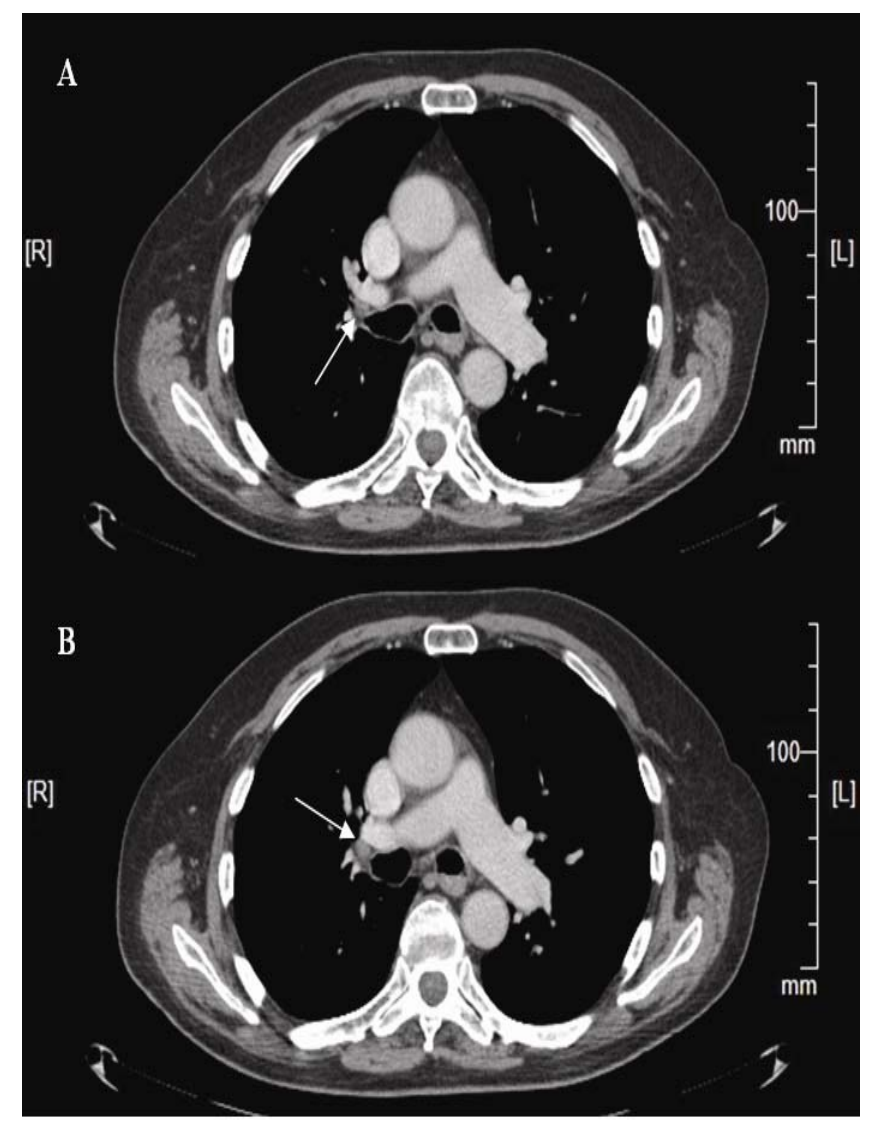

Figures 4. A, B. CT scan of the thorax showing a $28 \mathrm{~mm}$ lesion (arrow) surrounding the right bronchus intermedius.

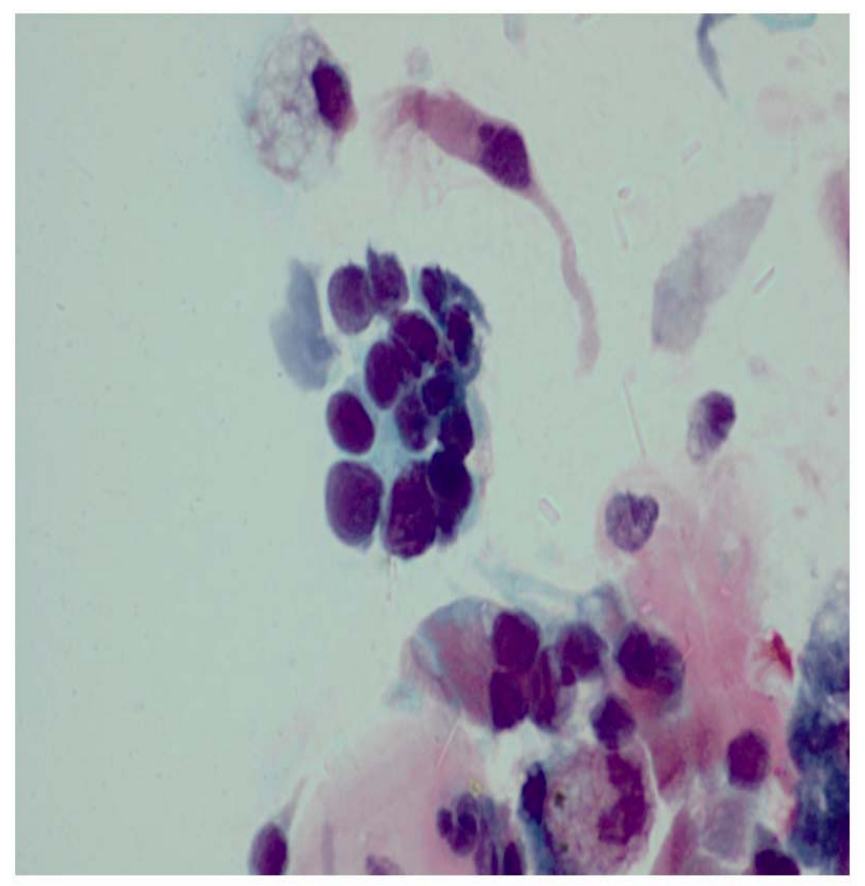

Figure 5. Bronchoalveolar lavage fluid cytology $(\times 600)$ showing small cell lung cancer cells. 


\section{Discussion}

Small-cell lung carcinoma (SCLC) is a high-grade neuroendocrine lung neoplasm accounting for $20 \%$ of lung cancers. It is associated with a poor prognosis, even after multimodal treatment has been employed. It has a neuroendocrine cellular origin with tumour cells usually expressing peptide hormones leading to a wide range of paraneoplastic syndromes, such as syndrome of inappropriate antidiuretic hormone secretion and syndrome of ectopic adrenocorticotropic hormone production.

Our patient had significantly high levels of serum chromogranin A. This is usually associated with either gastrointestinal neuroendocrine tumours or lung neuroendocrine tumours. Chromogranin A was found to be a prognostic marker for both staging and survival in SCLC; with a shorter survival time in patients with a level of more than $56 \mathrm{ng} / \mathrm{ml}{ }^{[1]}$. Besides chromogranin A, other neuroendocrine disease markers for SCLC can potentially include neuron-specific enolase, pro-gastrin-releasing peptide (not gastrin itself), cytokeratin-19 CYFRA 21-1, synaptophysin, creatine kinase BB, and neural cell adhesion molecule. Some of these molecules are released into the circulation and might proof useful as tumour markers in SCLC ${ }^{[2]}$. An interesting and uncommon feature about this case is the presentation of SCLC with isolated ipsilateral axillary lymph node metastases. There was no cervical, supraclavicular or mediastinal node involvement. This only occurs very rarely in bronchogenic carcinomas, with an incidence of $0.75 \%{ }^{[3,4]}$.

On the other hand, Ménétrier's disease (also known as hypoproteinaemic hypertrophic gastropathy) is a rare, acquired, premalignant disease of the stomach. There are multiple pathologic associations with Ménétrier's disease, including viral, bacterial infections and autoimmune disease. The medical literature also suggests an association between Ménétrier disease and malignancy, especially neuroendocrine neoplasms ${ }^{[5]}$. An exhaustive list of associations includes: 1) adenocarcinoma of the pancreas ${ }^{[6,7]}$, 2) APUD cell adenomas ${ }^{[8]}, 3$ ) Kaposi's sarcoma ${ }^{[9]}$, 4) stomach carcinoid ${ }^{[10]}, 5$ ) multiple endocrine adenomatosis originating in the neural crest, usually a pituitary adenoma ${ }^{[7,11]}, 6$ ) pancreatic islet cell tumour ${ }^{[7]}$, 7) chemodectoma ${ }^{[7]}$, 8) oesophageal granulosa cell tumour ${ }^{[12]}$, 9) gastric adenocarcinoma ${ }^{[13]}$, 10) gastric parietal cell carcinoma ${ }^{[14]}, 11$ ) mucinogenic carcinoma ${ }^{[15]}$ and 12) hepatocellular carcinoma ${ }^{[16]}$. Essentially, most of these tumours belong to group I ectopic hormone-producing tumours. SCLC is also classified as a group I tumour ${ }^{[17]}$.

It has been already postulated by Chang et al ${ }^{[7]}$ that neuroendocrine neoplasms may stimulate the gastric mucosa, through the secretion of hormones, thus contributing to the formation of giant gastric folds in Ménétrier's disease. In our case, the diagnosis of Ménétrier's disease was made 3 years prior to the SCLC diagnosis. Considering that SCLC exhibits rapid growth, aggressive behaviour and early widespread metastases, this hypothesis seems unlikely in our patient. Although survival of up to 14 years, has been previously documented for treated SCLC ${ }^{[18]}$.

Another hypotheses explaining the association of small cell lung carcinoma with Ménétrier's is the possibility of the neoplastic potential of Ménétrier's disease, which is in itself associated with excessive secretion of transforming growth factor alpha (TGF- $\alpha$ ) with increased signalling of epidermal growth factor receptor (EGFR), and a mild to moderate increase in serum gastrin levels in some cases.

Gastrin is also one of the hormones secreted by group I ectopic hormone-producing tumours, to which SCLC belongs. It is a hormone of the amine precursor uptake and decarboxylation (APUD) series ${ }^{[17]}$. However, serum gastrin will only be marginally elevated in small cell lung carcinoma patients (usually in $20 \%$ of patients) ${ }^{[19]}$. In our patient the levels were significantly elevated. Since there was no evidence of a gastrinoma or Zollinger Ellison Syndrome, a plausible explanation for this level of hypergastrinaemia is the Ménétrier's disease itself. Koh et al found that transgenic overexpression of gastrin in mice resulted in a significant increase in the prevalence and growth of bronchoalveolar carcinoma ${ }^{[20]}$. Researchers from the Imperial College in London have demonstrated that gastrin can stimulate the proliferation of cells outside the gastrointestinal tract, contributing to clonal growth in small cell lung cancer, by acting as a direct growth factor through gastrin/CCKB receptors ${ }^{[2]}$. These findings increase the possibility that Ménétrier's disease itself could have contributed to the development of small cell lung cancer in this patient. 
Our patient is a lifelong smoker with a 30 pack-year history, and SCLC is strongly associated with tobacco smoking. Moreover poorly differentiated neuroendocrine carcinoma such as SCLC may produce autocrine growth factors such as bombesin thus conferring autonomy, and might grow regardless of external hormonal stimuli ${ }^{[22]}$. So, the concurrence of these two conditions could have also been completely coincidental. However, our case raises the possibility that there could very well be an association between Ménétrier's disease and neuroendocrine tumours of the lung, with this case being the first such case reported in the literature.

\section{Acknowledgements}

The authors would like to thank Dr James Degaetano and Dr Alexandra Betts for providing the histological images.

\section{References}

[1] Petrovic M, Bukumiric Z, Zdravkovic V et al. The prognostic significance of the circulating neuroendocrine markers chromogranin A, pro-gastrin-releasing peptide, and neuron-specific enolase in patients with small-cell lung cancer. Medical Oncology. 2013 December; 31: 823. http://dx.doi.org/10.1007/s12032-013-0823-1

[2] Lamy PJ, Grenier J, Kramar A, Puiol JL. Pro-gastrin-releasing peptide, neuron specific enolase and chromogranin A as serum markers of small cell lung cancer. Lung Cancer. 2000 September 29; 3 197-203.

[3] Krishnamurthy A, Neelakantan V. Isolated axillary lymph node metastasis at presentation in bronchogenic carcinoma. J Can Res Ther .2012; 8: 161-2. http://dx.doi.org/10.4103/0973-1482.95206

[4] Satoh H, Ishikawa H, Kagohashi K, Kurishima K, Sekizawa K. Axillary lymph node metastases in lung cancer. Med Oncol. 2009; 26 (2): 147-50. http://dx.doi.org/10.1007/s12032-008-9097-4

[5] Odze R, Goldblum JR, Crawford JM. Surgical Pathology of the GI tract, Liver, Biliary tract and Pancreas.Book Review. Journal of Clinical Pathology. 2004 November; 57: 11-1344.

[6] Lightdale CJ, Bisordi W. Menetrier's disease and adenocarcinoma of the pancreas. Am J Gastroenterol. 1975 Dec; 64(6): 467-71.

[7] Chang PJ, Nino-Murcia M, Kosek J. Polypoid Menetrier's disease associated with acromegaly. Gastrointest Radiol. 1990 Winter; 15(1): 61-3. http://dx.doi.org/10.1007/BF01888737

[8] Moulias R, Noble JP, Auriol M, Ernst D et al. Cutis verticis gyrata, hypertrophic gastritis, motrice diarhea, and horse's tall syndrome, a new association an apudoma (carcinoid or chemodectoma). Sem Hop. 1979 Mar 8-15; 55(9-10): 435-41.

[9] DiSibio G, McPhaul LW, Sarkisian A, Van Pham B, French SW. Ménétrier's disease associated with Kaposi's sarcoma. Exp Mol Pathol. 2008 Dec; 85(3): 160-4. http://dx.doi.org/10.1016/j.yexmp.2008.09.001

[10] Sarrazin A, Simon J, Bousquet A case of Menetrier's disease with a microscopic carcinoid tumor of the stomach. Arch Fr Mal App Dig. 1971 Jun-Jul; 60(6): 331-6.

[11] Kenney F, Malcolm B, Dockery M, Waugh J: Giant hypertrophy of gastric mucosa: a clinical and pathological study. Cancer. 1954; 7: 671-681. http://dx.doi.org/10.1002/1097-0142(195407)7:4<671::AID-CNCR2820070407>3.0.CO;2-1

[12] Gatineau-Sailliant G, Roche H, Gaudric M, Prat B et al. Ménétrier's disease, granulosa cell tumor of the esophagus and colonic polyps. Gastroenterol Clin Biol. 1987 Feb; 11(2): 178-9.

[13] Sâadia B, Salna BH, Mohamed J, Amina M et al. Ménétrier's disease and gastric carcinoma. Tunis Med. 2005 Aug; 83(8): 499-502.

[14] Barbosa AJ, Nogueira AM, Leite VH, Lima Júnior GF et al. Parietal cell carcinoma of the stomach and Ménétrier's disease. Arq Gastroenterol. 1987 Jan-Mar; 24(1): 36-40.

[15] Syc S, Herba Z, Kondrak R. Coexistence of Menetrier's disease with early form of mucinogenic carcinoma Wiad Lek. 1975 Jan 1; 28(1): 51-4.

[16] Bruce F Scharschmidt. The natural history of hypertrophic gastropathy (Menetrier's disease). The American journal of Medicine, 63 1977, 644-647. http://dx.doi.org/10.1016/0002-9343(77)90210-8

[17] RJ Levine, SA Metz. A classification of ectopic hormone-producing tumours. Annals New York Academy of Sciences 230, 1974 1; 533-546. http://dx.doi.org/10.1111/j.1749-6632.1974.tb14488.x

[18] Kazumi Nishino. Small-cell lung carcinoma with long-term survival: A case report. Oncology Letters. 2011; 2: 827-830,

[19] Hansen M, Hansen HH, Hirsch FR, Arends J et al. Hormonal polypeptides and amine metabolites in small cell carcinoma of the lung, with special reference to stage and subtypes. Cancer. 1980 Mar 15; 45(6): 1432-7.

http://dx.doi.org/10.1002/1097-0142(19800315)45:6<1432::AID-CNCR2820450622>3.0.CO;2-Z 
[20] Koh TJ, Field JK, Varro A, Liloglou T et al. Glycine-extended gastrin promotes the growth of lung cancer.Cancer Res. 2004 Jan 1; 64(1): 196-201. http://dx.doi.org/10.1158/0008-5472.CAN-03-2112

[21] Sethi T, Rozengurt E. Gastrin stimulates Ca2+ mobilization and clonal growth in small cell lung cancer cells. Cancer Res. 1992 Nov 1; 52(21): 6031-5.

[22] Wistuba II, Gazdar AF, Minna JD. Molecular genetics of small cell lung carcinoma. Semin Oncol. 2001 Apr 28 (2 Suppl 4): 3-13. http://dx.doi.org/10.1016/S0093-7754(01)90072-7 